\title{
Revisional study on water mites of the family Harpagopalpidae K. Viets, 1924 (Acari: Hydrachnidia), with descriptions of new species from Cameroon and Madagascar
}

\author{
R. Gerecke \\ Biesingerstr. 11, D - 72070 Tübingen, Germany. E-mail : reinhard.gerecke@ uni-tuebingen.de
}

\begin{abstract}
Three new species of the genus Harpagopalpus are described from Madagascar, allowing a redefinition of diagnostic character states of the monotypic family Harpagopalpidae, previously known only from Western Africa (two species) and India (one species. The separation of the subgenera Harpagopalpus and Harpagopalpellus is supported by new characters. Harpagopalpus octoporus K.Viets, 1924 and $H$. tetraporus K.Viets, 1924 are redescribed and a lectotype is designated of $H$. octoporus. A fourth new species is described from Cameroon, based on a male specimen erroneously considered to be the female of $H$. octoporus by K. Viets.
\end{abstract}

Keywords : Diversity, tropical streams, Mouthpart morphology, systematics, Africa.

\section{Introduction}

Harpagopalpids are little-known Hydrachnidia so far recorded only from Western Africa (Harpagopalpus octoporus K.Viets, 1924: Cameroon, Liberia; $H$. tetraporus K.Viets, 1924: Cameroon) and India (H. indicus Cook, 1967: Kerala state). Four populations representing three additional species were detected during field work by the author and Tom Goldschmidt in several parts of Madagascar in 2001. The study of these mites not only contributes to the biogeographical knowledge of this particular region of the globe, but also allows a better understanding of the character states diagnostic for this clade and hence its position within the superfamily Arrenuroidea. Measurements are summarized in table 1.

\section{Family Harpagopalpidae}

Diagnosis: With character states of the superfamily Arrenuroidea sensu Cook (1974), i.e. idiosoma heavily sclerotized; genital field without movable genital flaps (Fig. 2 A); lateral eyes in lateral position, not encapsulated; palp uncate (Fig. 4). Idiosoma circular in dorsal view, males of several species with a truncated posterior margin, with or without a petiole (e.g. Fig. 2 A) extending dorsocaudally, pyriform in lateral view, elevated in the anterior part, but flattened caudally (Fig. 6 A). Whole lateral and ventral idiosomal surface covered by continuous sclerotization ("ventral shield"), separated from the roundish dorsal shield by a dorsal furrow (complete in females and in males of $H$. tetraporus, caudally fused with ventral shield in males of all other species). Gnathosomal bay narrow, flanked by strong, U-shaped internal sclerotization that extends caudally to an inverse T-shaped rod underlying the medial area of $\mathrm{Cx}-1$ (e.g. Fig. 5 B). Contour lines of coxae well defined, coxae forming three groups with $\mathrm{Cx}-1+2$ and $\mathrm{Cx}-3+4$ fused to each other on each side, $\mathrm{Cx}-1+2$ fused medially, embracing the gnathosomal bay (e.g. Fig. 5 B). Separation line Cx-2/3 may be well developed and with porosity or only little developed and smooth. CX-4 shifted laterally, separated from the genital field proper by an area with two glandular openings (the anterior one with setae placed medially, the posterior one with setae placed laterally to the gland pore). Insertions of IV-L shifted anteriorly and situated laterally to III-L insertions, ventrally covered by a rounded extension (Fig. 2 A). The genital field may be located in a genital bay, broadly embraced 
Table 1. Harpagopalpid mites, measurements of idiosoma and gnathosoma (in $\mu \mathrm{m}$ ).

\begin{tabular}{|c|c|c|c|c|c|c|c|c|c|c|c|c|c|c|}
\hline \multirow{3}{*}{$\begin{array}{l}\text { species } \\
\text { sample } \\
\text { sex }\end{array}$} & \multicolumn{5}{|c|}{ zebu } & \multirow{2}{*}{\multicolumn{2}{|c|}{$\begin{array}{l}\text { mandena } \\
\text { MD 78d }\end{array}$}} & \multicolumn{3}{|c|}{ ferroviarius } & \multirow{3}{*}{$\begin{array}{c}\text { toxotes } \\
\text { SMF } \\
43671 \\
\text { male }\end{array}$} & \multirow{3}{*}{\begin{tabular}{|c|} 
octoporus \\
SMF \\
43669 \\
male \\
\end{tabular}} & \multicolumn{2}{|c|}{ tetraporus } \\
\hline & \multicolumn{5}{|c|}{ MD 120} & & & \multicolumn{2}{|c|}{ MD 34c } & $\begin{array}{l}\text { MD } \\
38 d\end{array}$ & & & $\begin{array}{c}\text { SMF } \\
43674\end{array}$ & $\begin{array}{c}\text { tube } \\
\text { material }\end{array}$ \\
\hline & \multicolumn{3}{|c|}{ male } & \multicolumn{2}{|c|}{ female } & male & female & male & \multicolumn{2}{|c|}{ female } & & & male & male \\
\hline Idiosoma length & 900 & 950 & 840 & 1090 & 1010 & 920 & 1080 & 990 & 1070 & - & 680 & 640 & 630 & 500 \\
\hline Idiosoma width & 800 & 870 & 706 & - & 920 & 820 & 940 & 950 & 980 & - & 660 & 580 & 530 & 450 \\
\hline Cx field length & 515 & 537 & - & - & 540 & 560 & 560 & 515 & 425 & - & 430 & 370 & 410 & 315 \\
\hline Cx-3 width & 482 & 504 & - & - & 530 & 493 & 493 & 560 & 560 & - & 360 & 300 & 320 & 270 \\
\hline Cx field length/Cx-3 width & 1.07 & 1.07 & - & - & 1.02 & 1.14 & 1.14 & 0.92 & 0.76 & - & 1.19 & 1.23 & 1.28 & 1.17 \\
\hline Dorsal shield length & 850 & 840 & 760 & 920 & 940 & 730 & 950 & 760 & 660 & 616 & 680 & 590 & 570 & 450 \\
\hline Dorsal shield width & 580 & 605 & 560 & 670 & 660 & 560 & 680 & 624 & 580 & 549 & 530 & 440 & 400 & 330 \\
\hline Dorsal shield length/width & 1.47 & 1.39 & 1.36 & 1.37 & 1.42 & 1.30 & 1.40 & 1.22 & 1.14 & 1.12 & 1.28 & 1.34 & 1.43 & 1.36 \\
\hline Gnathosoma ventral length & - & 206 & - & - & - & - & 234 & - & 225 & 234 & & 250 & & 74 \\
\hline Chelicera basal segment length & - & 130 & - & 134 & 134 & - & 139 & - & 130 & 130 & & 65 & 100 & 78 \\
\hline Chelicera claw length & - & 128 & - & 125 & 130 & - & 139 & - & 130 & 132 & & 105 & 100 & 78 \\
\hline Chelicera height & - & 132 & - & 134 & 134 & 130 & 139 & - & 129 & 134 & & 80 & 103 & 80 \\
\hline Chelicera total length & - & 258 & - & 259 & 264 & - & 278 & - & 260 & 262 & & 170 & 200 & 156 \\
\hline Chelicera length/height & - & 1.95 & - & 1.93 & 1.97 & - & 2.00 & - & 2.02 & 1.96 & & 2.13 & 1.95 & 1.95 \\
\hline Chelicera basal segment/claw length & - & 1.02 & - & 1.07 & 1.03 & - & 1.00 & - & 1.00 & 0.98 & & 0.62 & 1.00 & 1.00 \\
\hline P-1 length & 25 & 27 & 25 & 34 & 25 & 31 & 34 & 34 & 31 & 34 & 21 & 20 & 19 & 16 \\
\hline P-1 height & 29 & 32 & 27 & 34 & 31 & 28 & 31 & 29 & 29 & 29 & 28 & 25 & 25 & 21 \\
\hline P-2 length & 76 & 74 & 65 & 72 & 67 & 81 & 85 & 76 & 69 & 72 & 58 & 58 & 53 & 41 \\
\hline P-2 height & 52 & 52 & 47 & 54 & 56 & 63 & 67 & 54 & 56 & 49 & 45 & 43 & 40 & 33 \\
\hline P-3 length & 40 & 40 & 41 & 38 & 49 & 45 & 51 & 49 & 45 & 47 & 45 & 40 & 38 & 24 \\
\hline P-3 height & 47 & 49 & 45 & 49 & 54 & 49 & 52 & 47 & 45 & 45 & 40 & 33 & 35 & 29 \\
\hline P-4 length & 69 & 78 & 72 & 81 & 81 & 83 & 85 & 78 & 78 & 74 & 60 & 53 & 60 & 46 \\
\hline P-4 height & 69 & 67 & 58 & 67 & 69 & 74 & 78 & 74 & 78 & 72 & 63 & 58 & 53 & 49 \\
\hline P-5 length & 58 & 63 & 63 & 63 & 67 & 67 & 69 & 76 & 74 & 69 & 63 & 58 & 53 & 44 \\
\hline P-5 height & 16 & 15 & 16 & 16 & 18 & 16 & 17 & 18 & 18 & 16 & 15 & 14 & 10 & 9 \\
\hline Palp total length & 268 & 282 & 266 & 288 & 289 & 307 & 324 & 313 & 297 & 296 & 246 & 228 & 221 & 171 \\
\hline$P-1$ relative length & 0.09 & 0.10 & 0.09 & 0.12 & 0.09 & 0.10 & 0.10 & 0.11 & 0.10 & 0.11 & 0.09 & 0.09 & 0.08 & 0.09 \\
\hline$P-2$ relative length & 0.28 & 0.26 & 0.24 & 0.25 & 0.23 & 0.26 & 0.26 & 0.24 & 0.23 & 0.24 & 0.23 & 0.25 & 0.24 & 0.24 \\
\hline$P-3$ relative length & 0.15 & 0.14 & 0.15 & 0.13 & 0.17 & 0.15 & 0.16 & 0.16 & 0.15 & 0.16 & 0.18 & 0.18 & 0.17 & 0.14 \\
\hline$P-4$ relative length & 0.26 & 0.28 & 0.27 & 0.28 & 0.28 & 0.27 & 0.26 & 0.25 & 0.26 & 0.25 & 0.24 & 0.23 & 0.27 & 0.27 \\
\hline$P-5$ relative length & 0.22 & 0.22 & 0.24 & 0.22 & 0.23 & 0.22 & 0.21 & 0.24 & 0.25 & 0.23 & 0.25 & 0.25 & 0.24 & 0.26 \\
\hline P-2/P-4 length ratio & 1.10 & 0.95 & 0.90 & 0.89 & 0.83 & 0.98 & 1.00 & 0.97 & 0.88 & 0.97 & 0.96 & 1.10 & 0.88 & 0.89 \\
\hline P-1 length/height & 0.86 & 0.84 & 0.93 & 1.00 & 0.81 & 1.11 & 1.10 & 1.17 & 1.07 & 1.17 & 0.77 & 0.80 & 0.75 & 0.76 \\
\hline P-2 length/height & 1.46 & 1.42 & 1.38 & 1.33 & 1.20 & 1.29 & 1.27 & 1.41 & 1.23 & 1.47 & 1.28 & 1.35 & 1.31 & 1.24 \\
\hline P-3 length/height & 0.85 & 0.82 & 0.91 & 0.78 & 0.91 & 0.92 & 0.98 & 1.04 & 1.00 & 1.04 & 1.13 & 1.23 & 1.07 & 0.83 \\
\hline P-4 length/height & 1.00 & 1.16 & 1.24 & 1.21 & 1.17 & 1.12 & 1.09 & 1.05 & 1.00 & 1.03 & 0.96 & 0.91 & 1.14 & 0.94 \\
\hline P-5 length/height & 3.63 & 4.20 & 3.94 & 3.94 & 3.72 & 4.19 & 4.06 & 4.22 & 4.11 & 4.31 & 4.17 & 4.18 & 5.25 & 4.89 \\
\hline
\end{tabular}

by the mediocaudal margins of $\mathrm{Cx}-4$ (Fig. $3 \mathrm{~A}$ ), or shifted caudally, with the anterior margin of the gonopore level with the posterior edge of Cx-4 (Fig. 3 B-C). Genital opening oval in shape, surrounded by an area of fine porosity with scattered short setae (Fig. 2 B). Numerous acetabula located on tongue-shaped areas originating from the gonopore area and in the lateral part of the idiosoma bent anteriorly, reaching the level of the insertion of IV-L (Fig. 6 A). Acetabula difficult to distinguish from normal body porosity (Fig. 2 B), but the area of their presence (corresponding to the genital plates of other Arrenuroidea) is recognizable, 

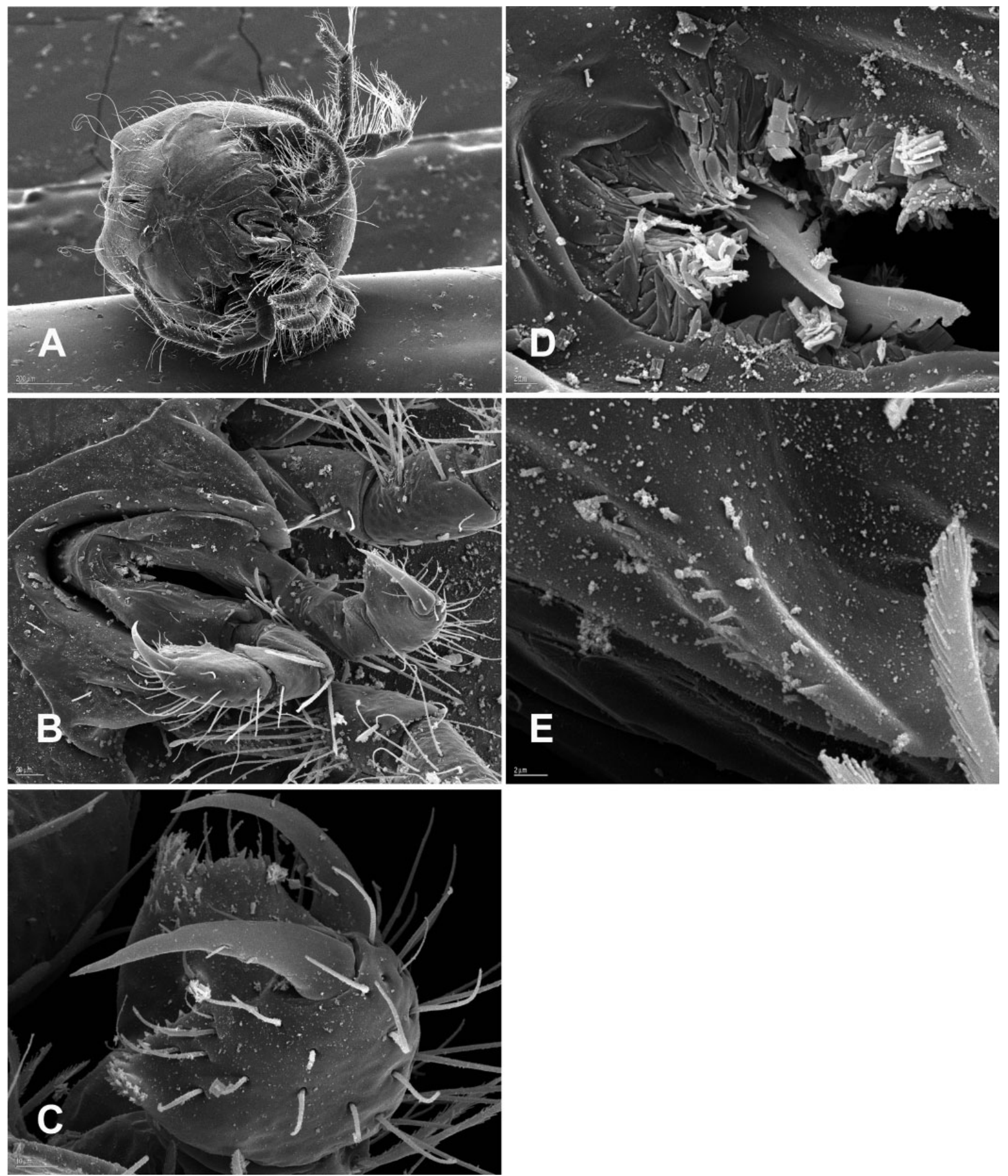

Fig. 1. Harpagopalpus zebu, male. A anteroventral view; B gnathosoma in anteroventral view; C distal palp segments; D basal part of the mouth opening with cheliceral claws and surrounding villi; E papillae on the lateral surface of the mouth opening. 

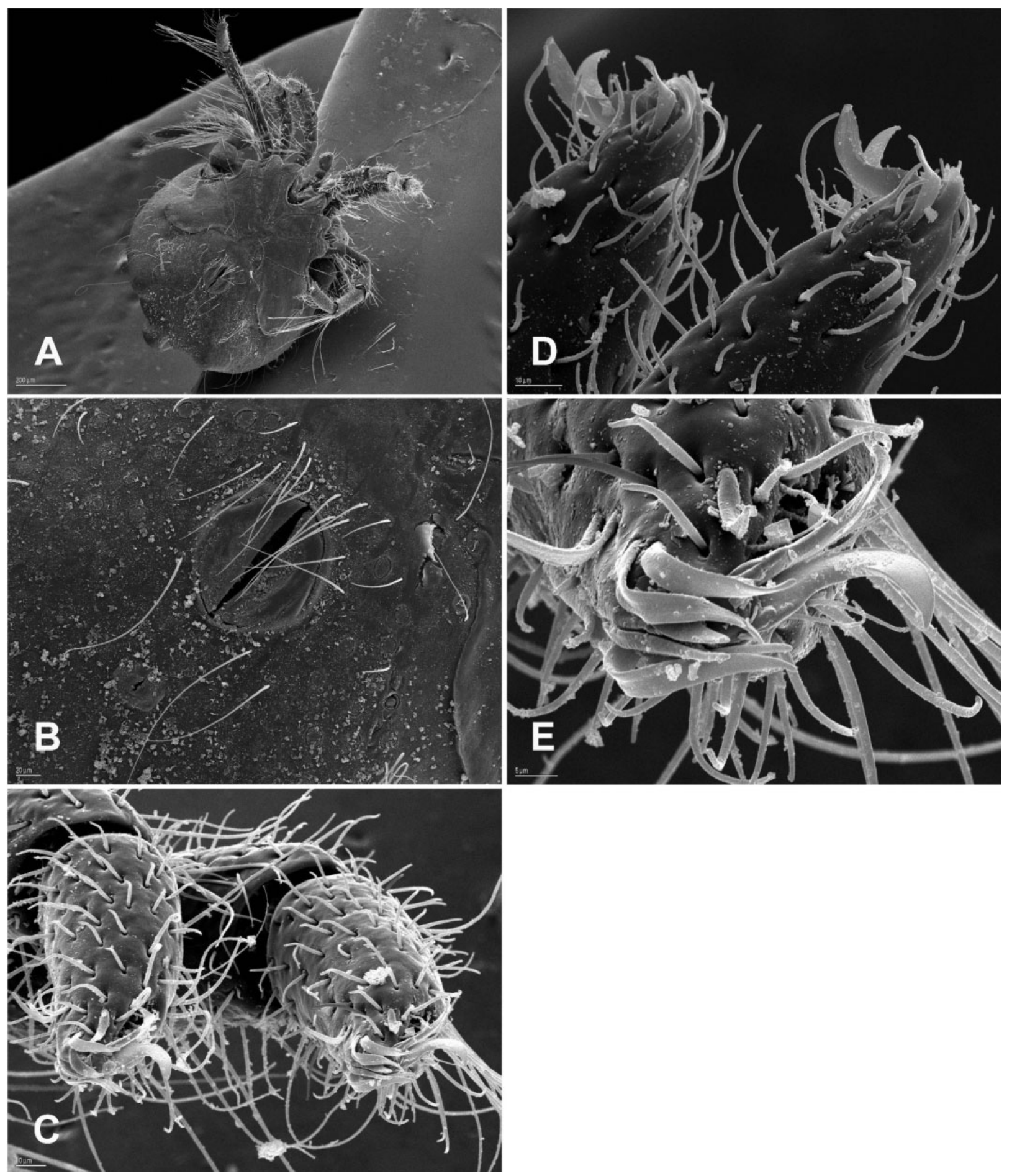

Fig. 2. Harpagopalpus zebu, male. A posteroventral view; B genital field; C terminal segments of I/II-L, anterior view; D terminal segments of I/II-L, lateral view; E. I-L, claws and surrounding setae. 
even in undissected specimens, by the presence of numerous long and fine setae. A low number of additional acetabula present in the gonopore, males with one to four pairs arranged on the lips flanking the genital opening (e.g. Fig. 2 B, Fig. 3 A, C, E), females with four pairs on a narrow sclerite strip surrounding the gonopore (Fig. 9 A). Male ejaculatory complex with all attributes typically found in Hydrachnidia (Fig. 6 B-C). Anterior keel little developed, but posterior keel very long, on the large proximal chamber proximally extending far over the level of the (well developed) proximal horns. Excretory pore in the area between gonopore and posterior idiosomal margin. Here and on the lateral surface flanking the genital field, 2-5 strong, long setae, more strongly developed in males than in females and characteristically bent anteriorly (e.g. Fig. 9 B). Glandulare flanking excretory pore associated with two setae in males, one in females.

Legs (Figs 2 C-E, 8) with simple claws and a luxuriant setation: distal segments 4-6 of I-II-L with a dense cover of fine, hair-like setae, those ventrally surrounding claw insertions are basally enlarged and willow-leaf shaped. I-L-3 and II-L-2/3 with groups of long, strong ventral setae. III-IV-L bearing long, strong swimming setae arranged in regular transverse rows, dorsally on III-L-3-5 and IV-L-5, both dorsally and ventrally on IV-L-3-4. Without notable sexual dimorphism in shape and setation of legs.

Extracted gnathosoma appearing as a very fragile framework (Figs 4 D, 7 B), probably representing only the inner armature of the gnathosoma proper, with the external sheath probably remaining attached to the idiosoma due to fusion to the inner margin of $\mathrm{Cx}-1$. External mouth opening very large, extending over most of the length of the gnathosomal bay (Fig. 1 B), basal part surrounded by a fringe of villi (Fig. 1 D), inner 'cheek' surface with scattered fine papillae (Fig. 1 E). Internal mouth opening with origin of pharynx shifted far proximally (visible in Fig. 4 D). Chelicera (Fig. 7 C) extremely modified in shape and very strong: basal segment stout, as high as long and with a finger-like distal extension. Claw apparently opposed by this extension, basally very thickened, distal part covered by a double line of fine, pointed denticles, those of the lateral row with their tips directed proximally, those of the medial row perpendicular, directed dorsally. Palp (Fig. 4, 7 A-B) compact, with segments 2-4 distally enlarged and P-4 forming a narrow ventrodistal extension opposing the strong, pointed P-5. Ventrodistal surface of P-4 characteristically covered by fine denticles and hair-like setae (Fig. 2 C). Additionally, $\mathrm{P}-1$ bearing one long dorsal seta, P-2 a characteristic pair of setae on the proximomedial surface and three dorsodistal setae, P-3 two strong dorsodistal setae, P-4 a dense cover of finer setae dorsally and laterally, and P-5 several fine setal pores, some of them visible at high (SEM) magnification only, but one longer, inserted ventrally in the proximal third.

Deutonymph (from K.Viets 1925) soft-bodied, with coxae in three groups as in adults, $\mathrm{Cx}-4$ triangular in shape. Provisional genital field bearing two platelets separated medially from each other by membranous integument. On each platelet, two acetabula located in parallel to the medial line. Mouthparts as in adults, but with setation less dense.

Discussion: Cook (1966) was the first to observe the acetabular fields in Harpagopalpus species characteristically extending between gonopore and IV-L insertion. Together with the unusual shape of chelicerae and palps, this character induced him to rank the former subfamily Harpagopalpinae K.Viets (of Athienemanniidae K. Viets) as a separate family (Cook 1974). In correspondence with the apomorphic character of its appendages, the construction of the gnathosoma is also unusual, being here interpreted as a fusion of the outer sheath with Cx-1, combined with a mobilization of the inner framework. This indicates that this monotypic family is a rather isolated clade.

Obviously, the state of several characters here described for the first time, mostly based on $H$. zebu sp. nov. (but observed also in specimens of the other species as far as allowed by the state of conservation), is not subject to large interspecific variability. No remarkable differences were found in the leg setation of the species presented here, and the shape of gnathosoma and its appendages is rather homogenous. Apparently, the unique mouthparts of this species are highly adapted for the uptake of a very special kind of prey, and therefore do not allow for a wider range of speciesspecific adaptation. A similar statement is not yet possible for the male ejaculatory complex which was dissected in only one of the three new species. In view of the different conformations of the external morphology in males, corresponding adaptations of the distal parts of the male gonoduct are well possible. It is likely that, with increasing knowledge about variability in Harpagopalpus species, the separation of females will prove difficult and the knowledge of the male sex will be necessary for species recognition.

The presence of acetabula both in the gonopore and on the flanking plates is also found in males of the arrenuroid families Hungarohydracaridae, Arenohydracaridae and Athienemannidae. Probably, this is an intermediate state between the plesiotypic arrangement 
of acetabula in the soft integument around the genital opening (Mideopsidae) and that of their location exclusively on to the flanking sclerite plates (Arrenuridae). The same type of setation of the P-2, with a pair of medial setae similar in shape placed in the basal part of the segment, is also found in Hungarohydracaridae and could indicate their close relationship with the Harpagopalpidae. This family includes males having acetabula only in the gonopore (genus Hungarohydracarus) or both in the gonopore and on the flanking plates (genus Balcanohydracarus), while they are restricted to flanking plates in all females. A phylogenetic interpretation is complicated due to the manifold morphological adaptations in the family group with this transitional character state. Evolutionary relations cannot be understood without considering the larval morphology, which is still poorly known in this clade and not yet studied in harpagopalpids. Obviously, the development of a cauda with an anchor process is a product of convergent evolution in arrenurids, in which this character state involves the area of the ventral plate and is accompanied by a sexual dimorphism in IV-L.

\section{Genus Harpagopalpus K.Viets, 1924}

Diagnosis: Only genus of the family, with the characters reported there.

Discussion: Lundblad (1941) proposed to place the two species known at his time in two subgenera, founded exclusively on differences in the number of acetabula in the male gonopore (four pairs in Harpagopalpus s.str., two pairs in Harpagopalpellus Lundblad, 1941). The significance of this character for the grouping of species in this taxon is surely low: male gonopore acetabula numbers are also reduced in one of the species described here from Madagascar, but with a strong intraspecific variability (one to three pairs within a single population). However, retaining the system proposed by Lundblad is suggested by another, more significant character. Males of Harpagopalpus tetraporus, the typus subgeneris of Harpagopalpellus, differ from those of all other species in having a complete dorsal furrow and lacking any modification of the posterodorsal part of the body, which means that the idiosomal outline is equally rounded rather than being truncated posteriorly. Furthermore they are characterized by the position of the genital field which is located between, rather than caudal to, the medial margins of $\mathrm{Cx}-4$. The interruption of the dorsal furrow in the posterior part of the idiosoma, accompanied by various morphological modifications in this part of the body (displacement of glandularia, formation of paired pits or appendages, concavity of the posterior margin), should be considered an autapomorphy of Harpagopalpus s.str. In this scenario, as well as with regard to the position of the genital field, Harpagopalpus (Harpagopalpellus) tetraporus represents the plesiomorphic condition. The presence of less than four pairs of acetabula in the male gonopore could be a further plesiomorphy, also retained in one representative of Harpagopalpus s.str. (H. zebu), or a character state independently evolved in both species from an octoacetabulate ancestor. The discovery of the multiplication of acetabula in the circumgenital field (Cook 1966) has widely invalidated the discussion of the phylogenetic significance of this character.

\section{Subgenus Harpagopalpus K.Viets, 1924}

Diagnosis: Both sexes: Gonopore located posteriad to level of Cx-4, not in a genital bay. Male dorsal furrow incomplete, dorsal shield fused posteriorly to ventral shield. Posterior glandularia on dorsal shield closer to each other than the anterior pairs. One to four pairs of acetabula in the gonopore.

\section{Harpagopalpus (Harpagopalpus) octoporus K.Viets, 1924}

Type series: Lectotype male, here designated, SMF 43670 (K.Viets 3154), Cameroon, Múhe River, 15.1.1916, undissected specimen mounted with dorsum facing the observer. Paralectotypes: same slide as lectotype, one male, partly dissected and damaged, in oblique position; SMF 43669 (K.Viets 3153), same locality and date as lectotype, 5 males, variously dissected.

Material examined: SMF 43675 (K.Viets 3186), same locality and date as lectotype, one deutonymph in strongly turbid mounting medium (described by K.Viets 1925, but excluded from the type series due to uncertain taxonomic attribution: three species of the genus were present at the same site).

Diagnosis: Male (female unknown, see discussion): Small, idiosoma length/width 640/580, posteriorly truncated, rather slender in outline (Fig. 3 D, the specimen in Fig. $3 \mathrm{C}$ is flattened, as is the case for all dissected specimens of the type series). Dorsal furrow horseshoe-shaped. Posterior glandularia of the dorsal shield shifted medially, distance to each other about the same as that to lateral margin. Mediocaudally from these glands, a pair of fine, hyaline, horn-shaped extensions located on the plate surface, not associated with a prominent socle. Gonopore with a row of four pairs of acetabula (Fig. 3 C). Paragenital acetabula mostly obscured by strong sclerotization, but setation extending far rostrally on the idiosomal flanks (Fig. 3 D), suggesting that the acetabula may reach the level 

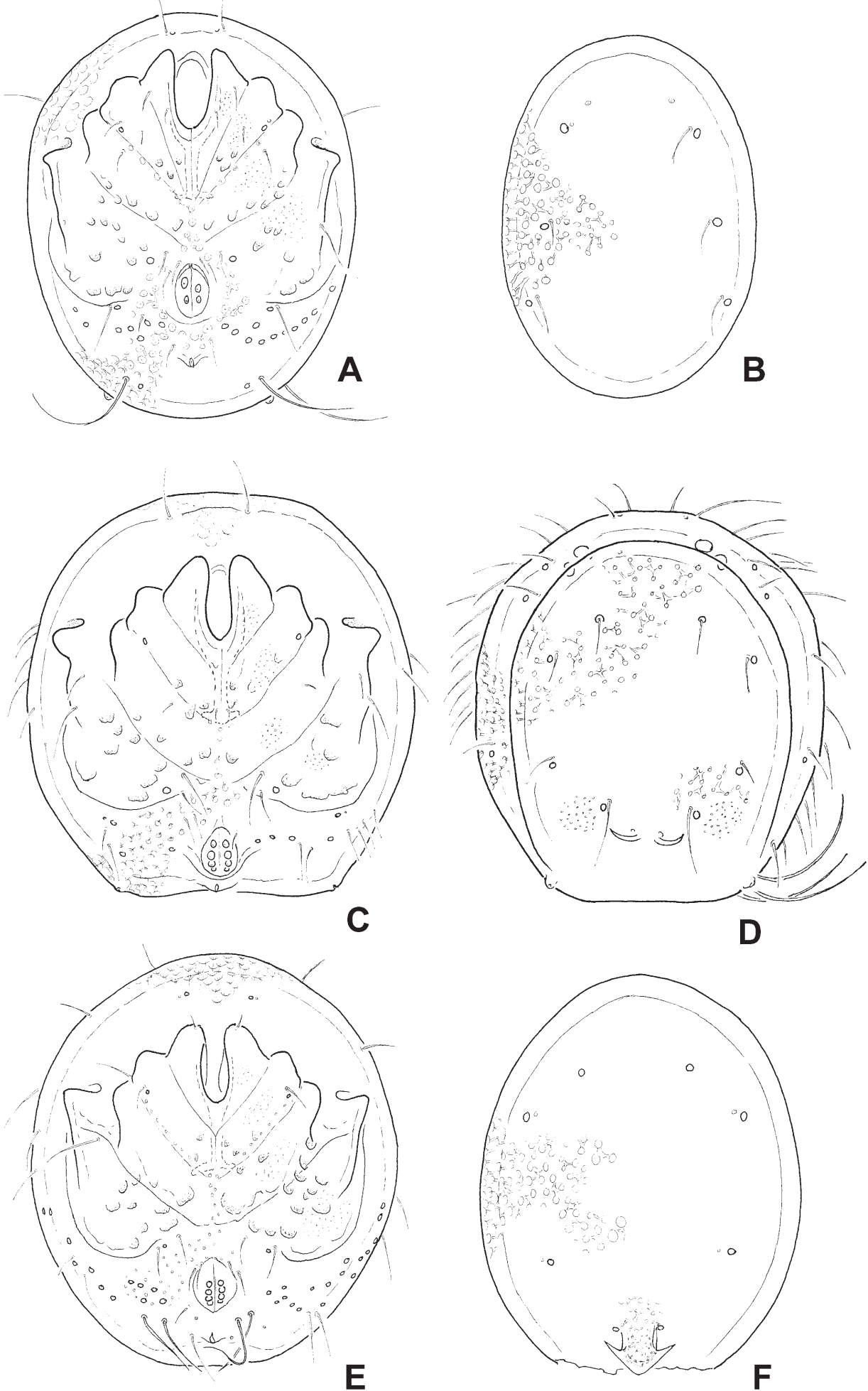

Fig. 3. Harpagopalpus species from Cameroon, males. A, C, E venter, B, D, F dorsum. A-B H. tetraporus; C-D H. octoporus; E-F H. toxotes. 
of the lateral eyes. P-4 with the distal setae and papillae arranged on a characteristic, equally rounded, distoventral extension. Chelicera rather slender (length/height 2.1) and with a particularly strong claw (basal segment/claw 0.6).

Discussion: This species is unique in the shape of the posterior part of the dorsal shield, with paired, horn-like extensions located on the shield surface proper, not on a projecting socle as is found in the two species described below. Obviously, the interpretation of a specimen collected together with the males of the type series as the corresponding female (K.Viets 1924) was erroneous. The lack of an ejaculatory complex is not a valid argument for considering it to be a female. This organ was generally lost by K.Viets during dissection and it is also absent from nearly all slides containing males of the type series. Both the comparative study of the new species described below and a comparison with representatives of related families show that the acetabula of Harpagopalpus females are not placed in the gonopore proper, but on sclerite strips fused to its lateral edges. Furthermore, the specimen interpreted as a female bears an anchor-shaped petiole on the posterior dorsal shield. Extensions of this type are secondary sexual characters exclusive to males in many Arrenuroid clades. The specimen on slide SMF 43671 is described below as the holotype of a species new to science. The attribution of a juvenile specimen from Liberia to H. octoporus (Cook 1966) is most probably correct. However, a further transformation of the posterodorsal petiole area by allometric growth is possible during the sclerotization after the adult moult. The record from Liberia should be confirmed by collecting well-sclerotized adult males.

\section{Harpagopalpus (Harpagopalpus) toxotes sp. n.}

Type series: Holotype male, SMF 43671 (K.Viets 3155), Cameroon, Múhe River, 15.1 .1916 (labelled: "H. octoporus Viets female Type").

Description: Male (female unknown): Small, idiosoma length/width $680 / 660 \mu \mathrm{m}$, posteriorly truncated (Fig. 3 E). Dorsal furrow horseshoe-shaped, rounded. Posterior glandularia of dorsal shield shifted far medially, the distance to each other less than that to the lateral margin, placed very close to the base of a petiole. This petiole is arrow-like and stout, caudally obtuseangled and with a pair of pointed, laterally-directed extensions. Gonopore with a row of four pairs of acetabula, slightly elevated posteriorly over the idiosoma surface, postgenital area shortened (Fig. 3 F). Paragenital acetabula mostly obscured by strong sclerotization. Setation on idiosomal flanks suggests that acetabula reach the level of IV-L-insertions. P-4 with distal setae and papillae arranged on a characteristic, equally rounded distoventral extension. Chelicera not measurable.

Discussion: Harpagopalpus toxotes is similar to $H$. octoporus in the palp shape and measurements, but differs in having the dorsal shield enlarged and its posterior part bearing an arrow-like, pointed petiole. Due to the generally bad state of conservation of the single specimen, the observation of further important characters is impossible. However, there is sufficient evidence that it is neither the female of $H$. tetraporus (see there), nor attributable to one of the other described species. At the type locality, it was found coexisting with two other species of the genus, $H$. tetraporus and $H$. octoporus.

Etymology: $\tau 0 \xi$ ó $\tau\rceil$ (Greek) = archer, referring to the arrow-shaped petiole.

\section{Harpagopalpus (Harpagopalpus) zebu sp. n.}

Type series: Holotype male, MNHN Paris, undissected, in Koenike's fluid, Madagascar 120d, Maromandia (Majunga), River Andranamalaza, $70 \mathrm{~m}$ a.s.1., $31.3^{\circ} \mathrm{C}, 0.023 \mathrm{mS} / \mathrm{cm}$; pool with a rocky shore, 21.10.2001, Gerecke \& Goldschmidt. Paratypes: same site and date, 2 males, one female dissected and slidemounted in Hoyer's fluid, 5 males undissected, in Koenike's fluid in MNHN Paris, 2 males dissected and slide-mounted in Hoyer's fluid, one male mounted and sputter-coated for SEM observation, in coll. Gerecke, Tübingen.

Description: Male: Idiosoma length/width 840950/706-870 $\mu \mathrm{m}$. In ventral view (Fig. 5 B), equally rounded anteriorly and laterally, caudally truncated. Caudal area straight or concave in lateral parts, medially with a compact, apically rounded appendage bearing a pair of weakly sclerotized but well developed horn-like projections, directed anteriorly (Fig. $2 \mathrm{~A}$, $5 \mathrm{~A})$; the insertion and size of these horns are variable (distance between tips: 126-166 $\mu \mathrm{m}$ ). In lateral view (Fig. 6 A), idiosoma anteriorly elevated and gradually flattened posteriorly, caudal appendage not distinctly set off from dorsal shield. In dorsal view (Fig. 5 A), dorsal furrow blurred in the posterior part of the idiosoma, dorsal and ventral sclerotization continuous in the caudal part, a pair of glandularia with their setae flanking the base of the appendage. Between Cx-2 and $\mathrm{Cx}-3$, and medially separating $\mathrm{Cx}-3+4$ from each other, is a Y-shaped strip of sclerite covered by large pores, such as are also found caudally, laterally and dorsally on the idiosomal sclerotization (Fig. 5 B). Gonopore (Fig. 2 B) oval, in most cases bearing three pairs of acetabula, but only two pairs or an asymmetri- 

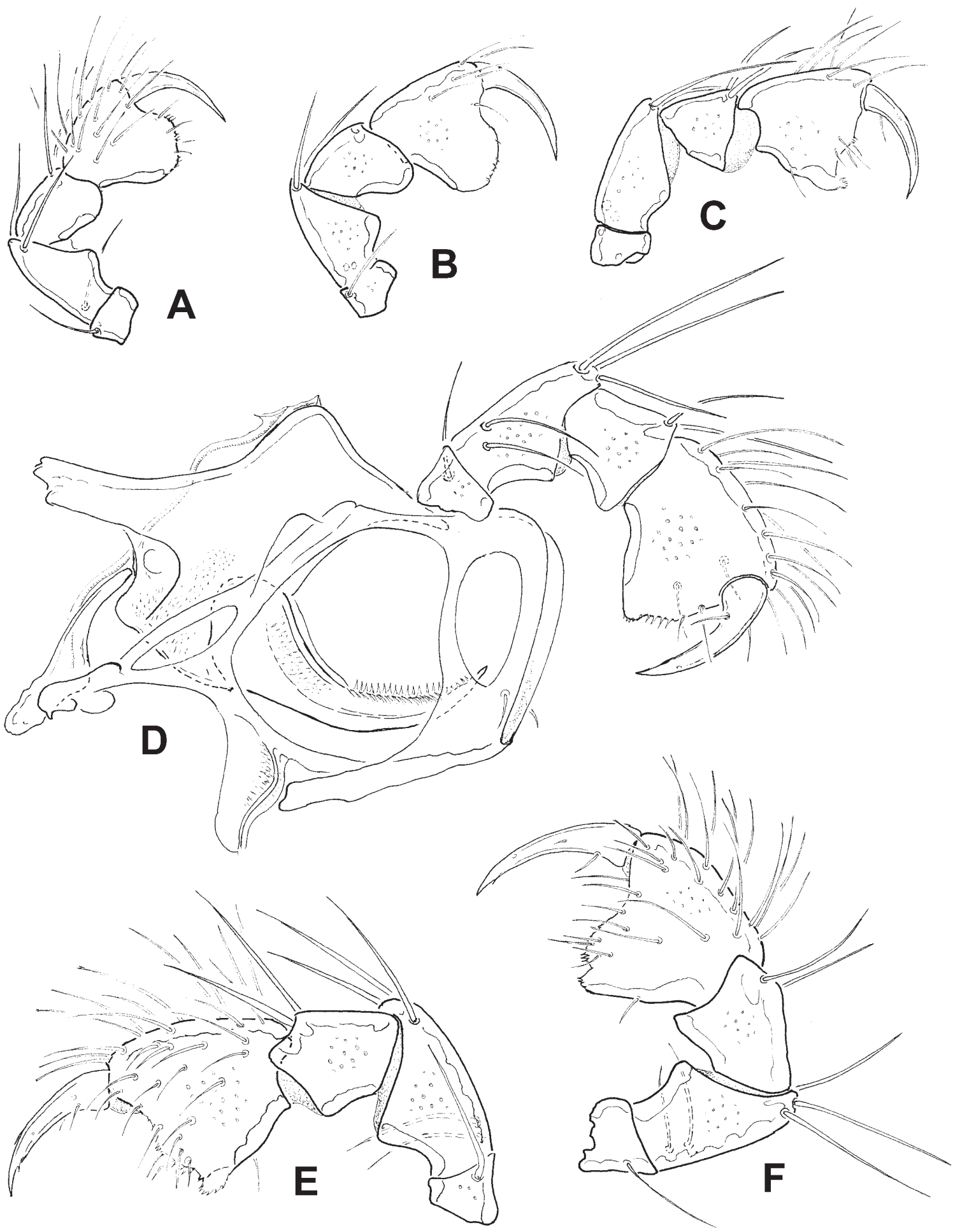

Fig. 4. Harpagopalpus mouthparts. A-C, E-F palps, D gnathosoma with right palp and chelicera in situ. A H. octoporus paralectotype male; B H. toxotes holotype; C H. tetraporus lectotype male; D H. zebu paratype male; E H. mandena male; F H. ferroviarius female. 


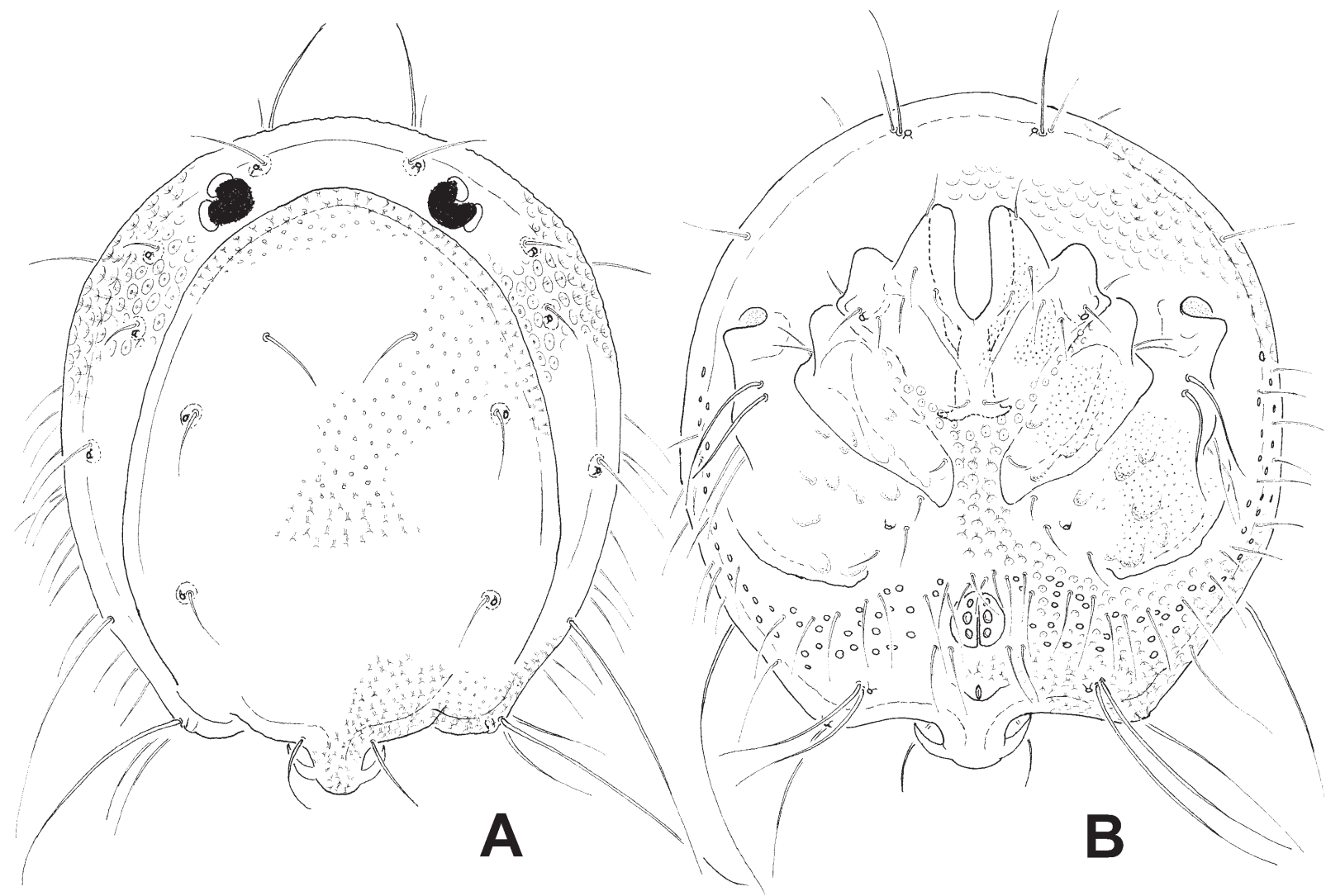

Fig. 5. Harpagopalpus zebu, paratype male. A dorsum; B venter.

cal arrangement $(2 / 3,1 / 3)$ can also be found. In the sclerotized area laterad of the gonopore, the acetabula extend on slender, arched areas which almost reach the level of insertions of IV-L (Fig. 2 B, 6 A). Ejaculatory complex (Fig. 6 B-C) rather large (length 378-410 $\mu \mathrm{m})$, anterior keel little developed, posterior keel long and, together with the large proximal chamber, extending proximally far over the proximal horns.

Leg setation as depicted for female (Fig. 8) - no sexual dimorphism evident.

Gnathosoma and its appendages as in Fig. 7 for the female. Gnathosomal base forming a tiny armature, with the outer sheath probably fused to the gnathosomal bay face of Cx-I, and impossible to extract. Chelicera very robust and with a fine porosity on both the basal segment and the claw. Basal segment projecting distally into a membranous extension which, in the unprepared specimen, is apparently in contact with the dorsodistal area of the gnathosoma, near the palp in- sertion. Palp (Fig. 4 D) with distal edge of P-4 rather straight, bearing only a slight concavity dorsally from the weakly projecting, denticulate ventrodistal tip.

Female: Differing from male in larger size (idiosoma length/width 1010-1090/920 $\mu \mathrm{m}$ ), in dorsal view having a completely circular idiosoma contour, a continuous dorsal furrow, completely separating dorsal and ventral shields, and in the absence of a caudal appendage (as depicted in Fig. $9 \mathrm{C}$ for H. mandena). Furthermore, as described in the generic diagnosis, gonopore without acetabula on the internal lips, but surrounded by a pair of narrow sclerites with 4 pairs of acetabula, fused to the gonopore edge (as depicted in Fig. 9 A for $H$. ferroviarius). Mouthparts and legs as shown in Figs. 7 and 8.

Discussion: Males of this species are unique in the presence of a petiole projecting over the posterior edge of the dorsal shield and bearing a pair of horn-like extensions bent anteriorly. The somewhat similar petiole 


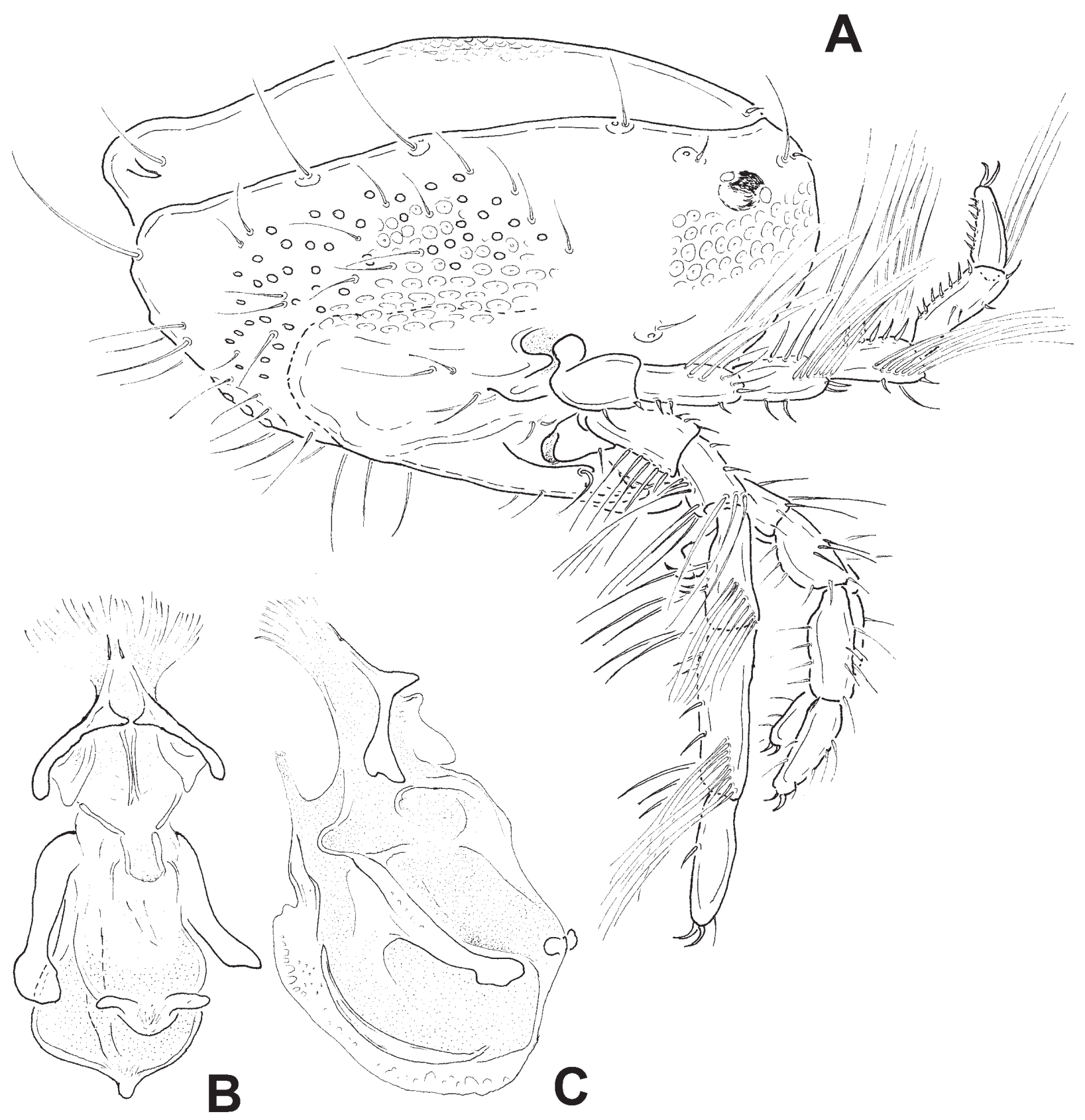

Fig. 6. Harpagopalpus zebu, paratype male. A lateral view; B-C ejaculatory complex, B anterior, C lateral view.

of H. toxotes (Fig. $3 \mathrm{~F}$ ) does not extend over the posterior edge of the idiosoma and its pointed lateral extensions are straight. In $H$. octoporus, a similar pair of horn-like curved posterodorsal extensions is developed, but they originate from the dorsal shield surface proper (Fig. 3 D), not from a stalk. Furthermore, both sexes of $H$. octoporus differ in the shape of the ventrodistal margin of P-4 (convexly protruding, not forming a distinct angle: Fig. 4 A-B) and having smaller dimensions (idiosoma $\mathrm{L}<700$, palp total $\mathrm{L}<250 \mu \mathrm{m}$ ). 


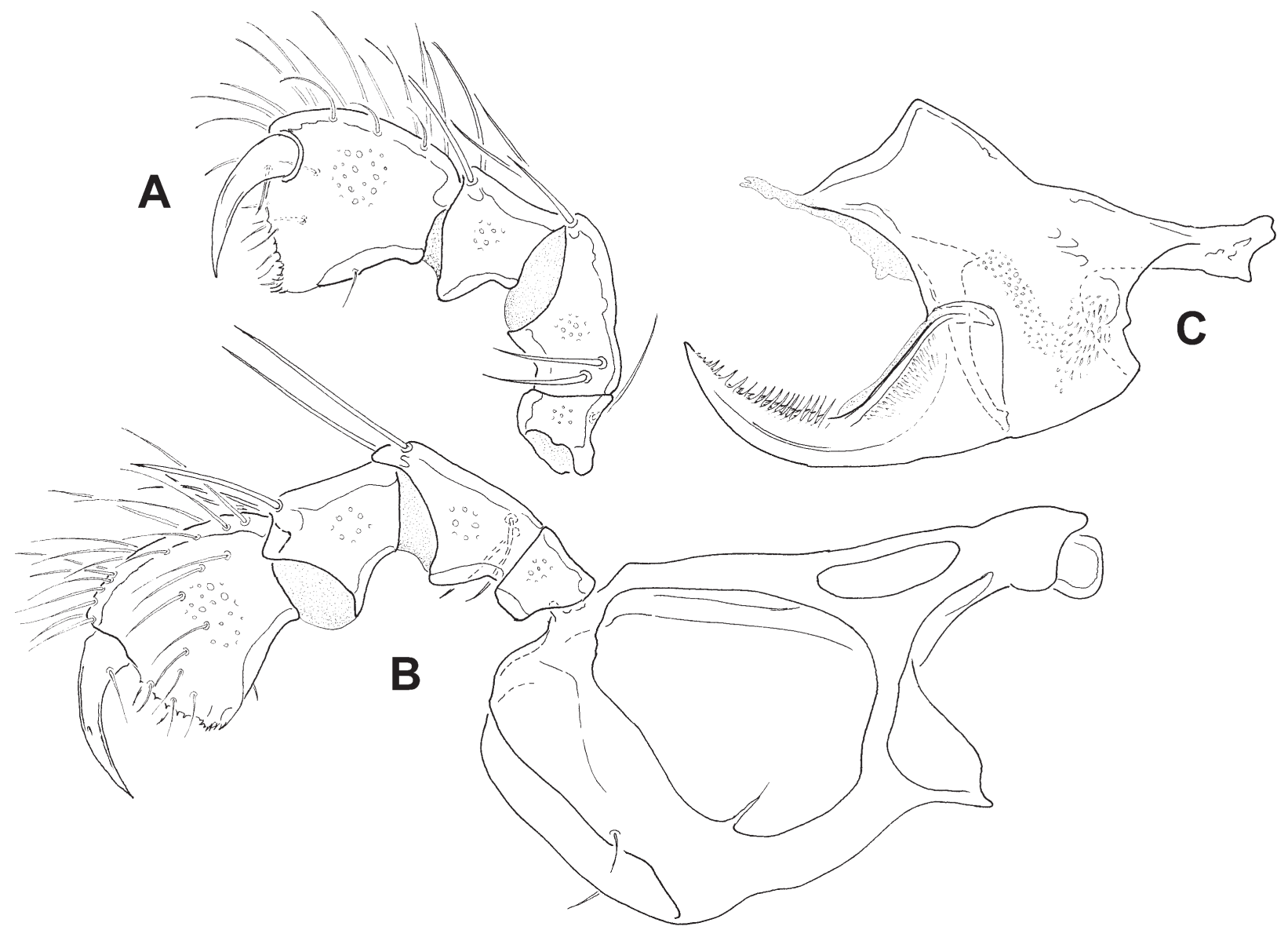

Fig. 7. Harpagopalpus zebu, paratype female, mouthparts. A right palp medially; B gnathosoma and left palp laterally; C chelicera.

Harpagopalpus tetraporus males are similar to $H$. ze$b u$ in the reduced number of acetabula in the gonopore and the shape of the palp (ventral margin of P-4 not protruding), but differ by their smaller dimensions (idiosoma $\mathrm{L}<600$, palp total $\mathrm{L}<220 \mu \mathrm{m}$ ) and by the characters diagnostic for the subgenus Harpagopalpellus (dorsal furrow complete, posterior dorsal shield without modifications, gonopore located in a genital bay). Most probably, the as yet undescribed female of these species will also differ from those of $H$. zebu in being smaller, and $H$. tetraporus females might additionally differ in the position of the gonopore. Harpagopalpus indicus, known only from a single female, differs from $H$. zebu in the shape of the palp (distal margin of P-4 not straight, but forming a distinct hump) and a more elongate gonopore placed in a genital bay.
Etymology: Named after the shape of the male petiole of this species, recalling the head of the bovines introduced to Madagascar and playing a prominent role in human culture there.

\section{Harpagopalpus (Harpagopalpus ) ferroviarius sp. $\mathbf{n}$.}

Type series: Holotype male: MNHN Paris, slide mounted in Hoyer's fluid, Madagascar 34c, Ranomena (Fianarantsoa), river NW from the $1.07 \mathrm{~km}$-railwaytunnel, $950 \mathrm{~m}$ asl., $16.3^{\circ} \mathrm{C}, 0.041 \mathrm{mS} / \mathrm{cm}$; pool, 19.08.2001 Gerecke \& Goldschmidt. Paratypes: MNHN Paris, one female, same locality and date; one female Madagascar 38d, Andrambovato (Fianarantsoa), stream $3 \mathrm{~km}$ E from the village, upstream from the cascade, $900 \mathrm{~m}$ a.s.1.; 20.08.2001 Gerecke \& Goldschmidt. 


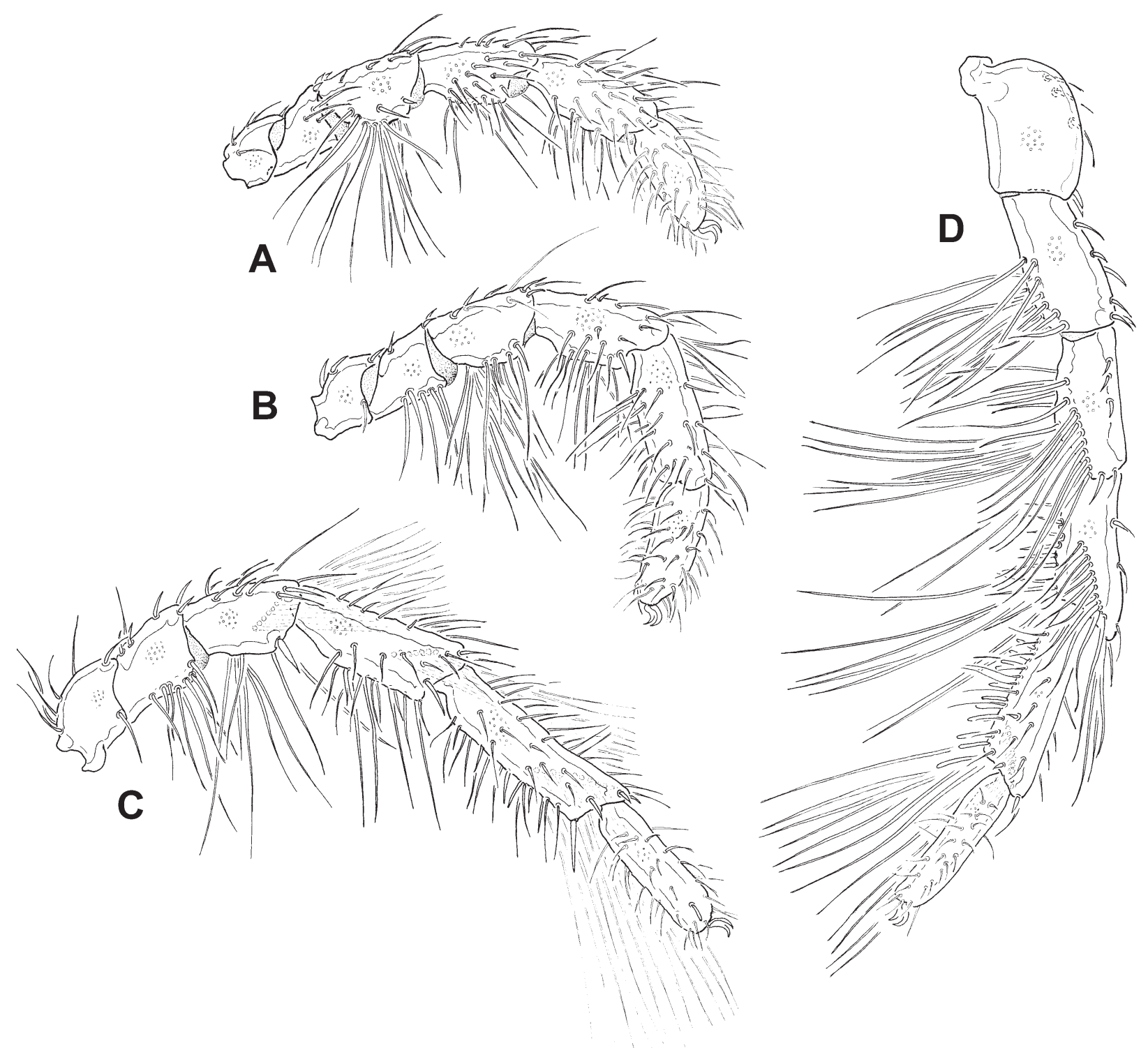

Fig. 8. Harpagopalpus zebu, paratype female, legs. A I-L; B II-L; C III-L; D IV-L.

Description: Male: Idiosoma length/width 990/950 $\mu \mathrm{m}$. In ventral view (Fig. 9 B), circular, but with flattened rostral and caudal margins, general aspect of body stout. Both dorsal shield (length/width ratio 1.2) and coxal field (length/width Cx-3 0.9) enlarged. No extension in the dorsocaudal area (Fig. 9 E). Instead, the pair of posterior glandularia of the dorsal shield is shifted rostrally and located on a line with, mediad of the central glands. Behind the posteromedial glands is a pair of grooves which enlarge and open caudally. In this area, dorsal shield broadly fused with ventral shield. Between Cx-2 and Cx-3, and medially separating Cx-3+4 from each other, a Y-shaped strip of sclerite covered by large pores, as are also found caudally, laterally and dorsally on the idiosoma sclerotization (Fig. 9 B). Gonopore oval, bearing four pairs of aceta- 


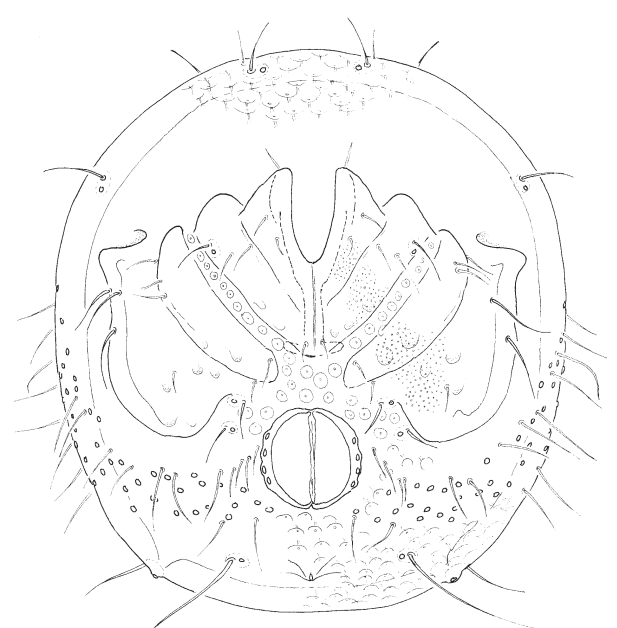

A

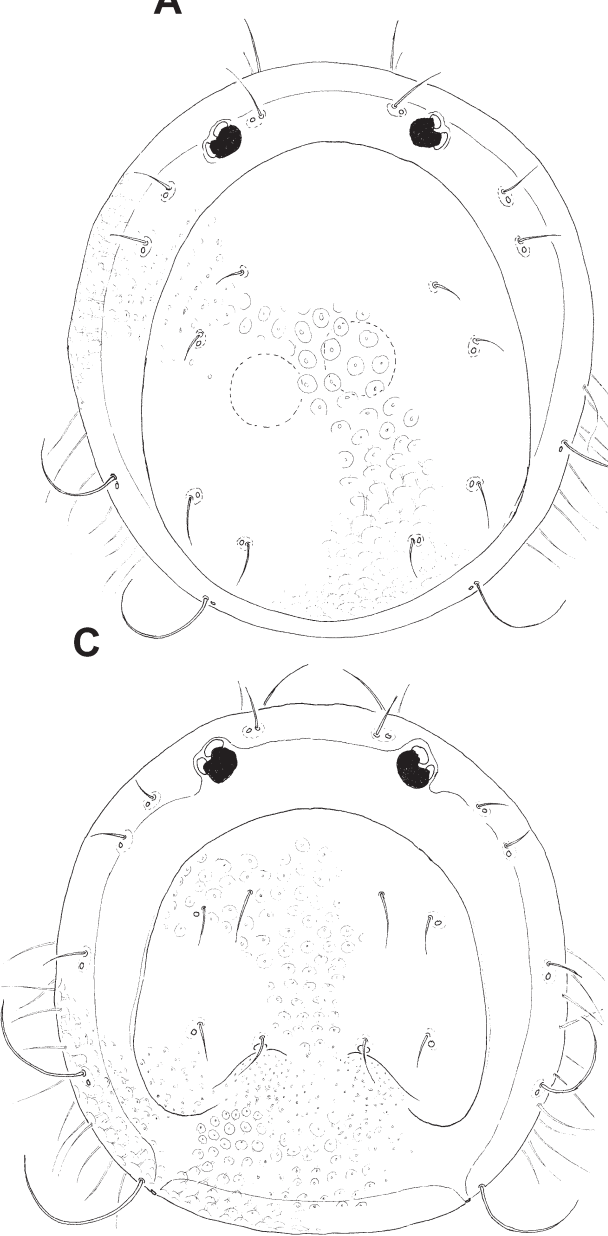

E

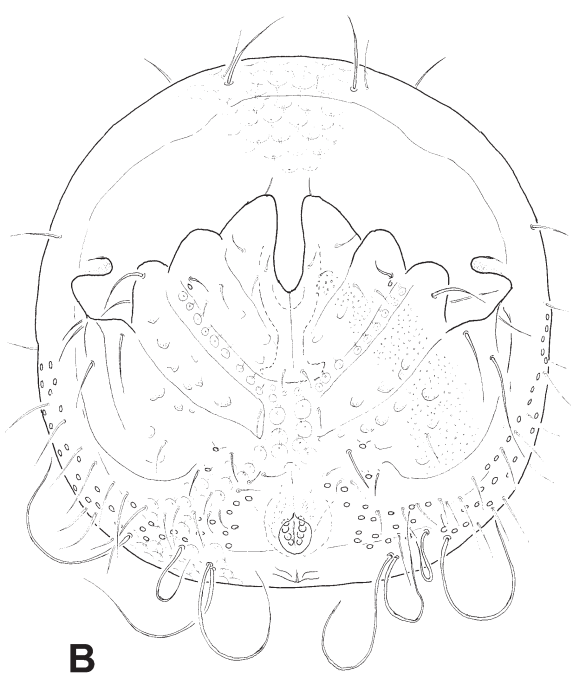


bula. Paragenital acetabula extending to level of insertions of IV-L. Length/width ratio of dorsal shield 1.2, ratio length coxal field/width Cx-3 0.9. Leg proportions and setation, as well as shape of gnathosoma and chelicera, as depicted for H. zebu. Palp as shown in Fig. $4 \mathrm{~F}$ for the female: distal margin of P-4 irregular, with a convex protrusion in its ventral part separated by an indentation from the denticulate ventrodistal tip of the segment.

Female: Differing from male in larger size (idiosoma length/width 1070/980 $\mu \mathrm{m}$ ), in dorsal view having a completely circular idiosoma contour, dorsal furrow complete, posteromedial glandularia on the dorsal shield located caudally from the posterolateral glandularia, not associated with a pair of grooves (as depicted in Fig. $9 \mathrm{C}$ for $H$. mandena). No acetabula located on lips of genital opening, but four pairs arranged on a pair of narrow sclerites fused to the edge of the gonopore (Fig. 9A). Length/width ratio of dorsal shield 1.1, ratio length coxal field/width $\mathrm{Cx}-3$ 0.8. Mature females with 8-14 eggs (diameter 170-190 $\mu \mathrm{m}$ ). No sexual dimorphism in legs and mouthparts.

Discussion: Harpagopalpus ferroviarius is characterized by the rather stout shape of the body (dorsal shield length/width ratio in the other species of the genus $\geq 1.3$ ). Males differ from all other species of Harpagopalpus s.str. in the absence of extensions on the posterior dorsal shield and from $H$. zebu in the presence of four pairs of acetabula on the genital lips. Both sexes may be distinguished from $H$. octoporus and $H$. toxotes by the larger dimensions and in having the distal edge of P-4 bearing a convex protrusion. This character is found in a similar form in $H$. indicus. Females of the latter species (male not yet described) differ from $H$. ferroviarius in having the gonopore more slender and lying in a genital bay, embraced by the mediocaudal margins of $\mathrm{Cx}-4$ for more than half of their length.

Etymology: Named after the "Ferrovie Côte Est", a unique railway crossing the area of the collecting site.

\section{Harpagopalpus (Harpagopalpus ) mandena sp. n.}

Type series: Holotype: male, MNHN Paris, slide mounted in Hoyer's fluid, Madagascar 78b2, Fort Dauphin (Tulear), Mandena (QMM area), River Amendano, near road bridge, $10 \mathrm{~m}$ a.s.1., $23.2^{\circ} \mathrm{C}$, $0.154 \mathrm{mS} / \mathrm{cm}$; pool, 13.09.2001, Gerecke \& Goldschmidt. Paratypes: MNHN Paris, same locality and date, one female slide mounted in Hoyer's fluid, one female undissected in Koenike's fluid.
Description: Male: Idiosoma length/width 920/820 $\mu \mathrm{m}$. In ventral view nearly circular, caudally truncated without a projecting caudal petiole. Dorsal shield (length/width ratio 1.3) and coxal field (length/width Cx-3 1.1) not particularly enlarged. Dorsal shield broadly fused posteriorly to ventral shield (Fig. 9 D). Posteromedial glandularia located on a line with the posterolateral glandularia (which lack setae in the specimen studied). Between the posteromedial glandularia lies a blunt, obtuse-angled projection directed caudally, accompanied at its caudolateral base by a pair of enlarged pores of uncertain identity. Between $\mathrm{Cx}-2$ and $\mathrm{Cx}-3$, and medially separating $\mathrm{Cx}-3+4$ from each other, an Y-shaped sclerite covered by large pores as are also found caudally, laterally and dorsally on the idiosomal sclerotization (Fig. 9 F). Gonopore oval, bearing four pairs of acetabula. Paragenital acetabula extending only a little beyond caudal margins of $\mathrm{Cx}-4$. Leg proportions and setation, as well as shape of gnathosoma and chelicera, as depicted for H. zebu. Palp as shown in Fig. 4 E: distal margin of P-4 irregular, ventral part extending convexly and with denticulate ventrodistal tip of the segment distinctly offset.

Female: Differing from male in larger dimensions (idiosoma length/width 1080/940 $\mu \mathrm{m}$ ), a completely circular idiosoma contour in dorsal view, a complete dorsal furrow, and the posteromedial glandularia on the dorsal shield located caudally from the central glandularia, not associated with an obtuse-angled medial extension. Four pairs of acetabula on paired narrow sclerites fused to the edge of the gonopore. Mature female with 5 eggs (diameter $140 \mu \mathrm{m}$ ). Length/width ratio of the dorsal shield 1.4 , ratio length coxal field/width $\mathrm{Cx}-3$ 1.1. No sexual dimorphism in legs and mouthparts.

Discussion: Males of $H$. mandena differ from all other species of the genus in the presence of an obtuse-angled projection lacking paired lateral extensions on the posterior dorsal shield. They are similar to males of $\mathrm{H}$. octoporus, $H$. toxotes and $H$. ferroviarius in the presence of four pairs of acetabula on the genital lips. Both sexes of $H$. octoporus and $H$. toxotes differ from $H$. mandena in being smaller and by the convexly protruding, not straight, ventral margin of P-4, while those of $\mathrm{H}$. ferroviarius differ in the stouter shape of the idiosoma.

The convex protrusion of the distal edge of P-4, characteristically developed in $H$. ferroviarius and $H$. indicus, is expressed more weakly in the three available specimens of $H$. mandena, which instead bear a more distinctly projecting ventrodistal extension. Further 
Table 2. Harpagopalpid mites, measurements of legs (in $\mu \mathrm{m}$ ).

\begin{tabular}{|c|c|c|c|c|c|c|c|c|}
\hline \multirow[b]{3}{*}{ sample } & \multicolumn{8}{|c|}{ H. zebu } \\
\hline & \multicolumn{3}{|c|}{ |-Leg } & \multicolumn{2}{|c|}{ II-Leg } & \multicolumn{3}{|c|}{ III-Leg } \\
\hline & \multicolumn{8}{|c|}{ MD 120} \\
\hline $\operatorname{sex}$ & \multicolumn{2}{|c|}{ male } & female & male & female & \multicolumn{2}{|c|}{ male } & female \\
\hline segment 1 length & 67 & 63 & - & 81 & 72 & 105 & 105 & 100 \\
\hline segment 1 height & 67 & 63 & - & 69 & 65 & 78 & 81 & 81 \\
\hline segment 2 length & 52 & 45 & - & 67 & 56 & 100 & 90 & 83 \\
\hline segment 2 height & 63 & 61 & - & 69 & 65 & 78 & 76 & 69 \\
\hline segment 3 length & 100 & 94 & - & 105 & 96 & 121 & 121 & 114 \\
\hline segment 3 height & 63 & 61 & - & 65 & 65 & 69 & 76 & 65 \\
\hline segment 4 length & 130 & 123 & 119 & 138 & 130 & 172 & 172 & 168 \\
\hline segment 4 height & 65 & 56 & 61 & 67 & 63 & 72 & 74 & 63 \\
\hline segment 5 length & 145 & 138 & 134 & 161 & 148 & 230 & 235 & 209 \\
\hline segment 5 height & 61 & 54 & 54 & 61 & 54 & 61 & 63 & 54 \\
\hline segment 6 length & 125 & 119 & 121 & 136 & 134 & 187 & 183 & 168 \\
\hline segment 6 height & 49 & 43 & 45 & 49 & 45 & 54 & 56 & 40 \\
\hline total length & 619 & 582 & - & 688 & 636 & 915 & 906 & 842 \\
\hline
\end{tabular}

\begin{tabular}{|c|c|c|c|c|c|c|c|c|c|c|c|c|}
\hline \multirow{4}{*}{$\begin{array}{l}\text { species } \\
\text { sample } \\
\text { sex }\end{array}$} & \multicolumn{5}{|c|}{ H. zebu } & \multicolumn{3}{|c|}{ H. ferroviarius } & \multicolumn{2}{|c|}{ H. mandena } & \multicolumn{2}{|c|}{ H. tetraporus } \\
\hline & \multicolumn{12}{|c|}{ IV-Leg } \\
\hline & \multicolumn{5}{|c|}{ MD 120} & \multicolumn{2}{|c|}{ MD 34c } & MD 38d & \multicolumn{2}{|c|}{ MD 78d } & $\begin{array}{l}\text { SMF } \\
3167\end{array}$ & $\begin{array}{c}\text { tube } \\
\text { material }\end{array}$ \\
\hline & \multicolumn{3}{|c|}{ male } & \multicolumn{2}{|c|}{ female } & male & \multicolumn{2}{|c|}{ female } & male & female & male & male \\
\hline segment 1 length & 145 & 136 & 132 & 134 & 141 & 153 & 144 & 139 & 135 & 143 & - & 76 \\
\hline segment 1 height & 94 & 90 & 87 & 83 & 96 & 90 & 76 & 76 & 90 & 94 & - & 54 \\
\hline segment 2 length & 123 & 116 & 112 & 130 & 121 & 121 & 121 & 112 & 130 & 130 & - & 69 \\
\hline segment 2 height & 83 & 76 & 78 & 72 & 76 & 85 & 72 & 76 & 81 & 81 & - & 54 \\
\hline segment 3 length & 141 & 134 & 128 & 134 & 141 & 153 & 144 & 139 & 148 & 148 & - & 76 \\
\hline segment 3 height & 63 & 58 & 58 & 61 & 65 & 76 & 58 & 58 & 60 & 63 & - & 43 \\
\hline segment 4 length & 168 & 165 & 161 & 172 & 168 & 184 & 180 & 167 & 184 & 189 & 120 & 90 \\
\hline segment 4 height & 61 & 58 & 54 & 58 & 58 & 76 & 63 & 60 & 58 & 58 & 38 & 34 \\
\hline segment 5 length & 180 & 180 & 170 & 185 & 187 & 225 & 220 & 211 & 220 & 229 & 125 & 100 \\
\hline segment 5 height & 54 & 49 & 45 & 52 & 52 & 54 & 49 & 49 & 49 & 46 & 33 & 27 \\
\hline segment 6 length & 163 & 163 & 145 & - & 161 & 202 & 184 & 184 & 224 & 206 & 133 & 105 \\
\hline segment 6 height & 43 & 45 & 38 & - & 40 & 41 & 32 & 36 & 33 & 32 & 21 & 18 \\
\hline total length & 920 & 894 & 848 & - & 919 & 1038 & 993 & 952 & 1041 & 1045 & - & 516 \\
\hline segment 3 length/height & 2.2 & 2.3 & 2.2 & 2.2 & 2.2 & 2.0 & 2.5 & 2.4 & 2.5 & 2.3 & 3.2 & 2.6 \\
\hline segment 4 length/height & 2.8 & 2.8 & 3.0 & 3.0 & 2.9 & 2.4 & 2.9 & 2.8 & 3.2 & 3.3 & 3.8 & 3.7 \\
\hline segment 5 length/height & 3.3 & 3.7 & 3.8 & 3.6 & 3.6 & 4.2 & 4.5 & 4.3 & 4.5 & 5.0 & 6.2 & 5.8 \\
\hline
\end{tabular}

populations should be studied in order to verify the intraspecific stability of this rather minute difference. Females of $H$. indicus (male not yet described) differ from $H$. mandena in the gonopore being more slender and lying in a genital bay, embraced for more than half their length by the mediocaudal margins of Cx-4.

Etymology: Named after the Mandena area, a coastal forest surrounding the type locality of this species. 


\section{Subgenus Harpagopalpellus Lundblad, 1941}

Diagnosis: Both sexes: Gonopore located in a genital bay, embraced by mediocaudal margins of $\mathrm{Cx}-4$. Male: Dorsal furrow complete, dorsal shield not fused to ventral shield. Posterior glandularia on the dorsal shield further from each other than the anterior pairs. Only two pairs of acetabula in the gonopore.

\section{Harpagopalpus (Harpagopalpellus) tetraporus K.Viets, 1924}

Type series: Lectotype male, SMF 43674 (K.Viets 3167), Kamerun, Fluß Sango, 20.1.1916, dissected and slide mounted in glycerine jelly. Paralectotypes: SMF 43672 (K.Viets 3156), Kamerun, Fluß Múhe, 15.1.1916, 4 males (one undissected); SMF 43673 (K.Viets 3157), Kamerun, Fluß Kóngulu, 12.1.1916, 3 males dissected; same locality as SMF 43673, one male dissected and slide mounted in Hoyer's fluid by Gerecke in 2005 , one male and one deutonymph undissected.

Diagnosis: Male (female unknown): Small and rather slender (Fig. 3 A-B), idiosoma length/width 500$630 / 450-530 \mu \mathrm{m}$, coxal field length/Cx-3 width ratio 1.2-1.3, dorsal shield length/width ratio 1.4. Dorsal shield oval, with anterior glandularia located close to each other, central glandularia at moderate distance, posterior glandularia far apart. Along the suture lines separating $\mathrm{Cx}-2$ from $\mathrm{Cx}-3$, and medially between $\mathrm{Cx}-$ 3 , only a few scattered pores, much fewer than the general idiosoma porosity. Gonopore with two pairs of acetabula, generally equal in size, but occasionally asymmetrical as in Fig. 3 A. Paragenital acetabula mostly obscured by strong sclerotization and no setation visible that could indicate their lateral extension (Fig. 3 A, B), not even in the newly dissected specimen from the vial collection, which suggests that these acetabula may be less numerous and more restricted than in other species of the genus. P-4 distal edge with a central tip separating a dorsal and a ventral concave area, and a ventrodistal extension covered by setae and papillae (Fig. 4 C). Chelicera as depicted in Fig. 7 C for $H$. zebu.

Discussion: The ejaculatory complex is preserved in only one of the specimens dissected by K.Viets, indicating that he did not take care of this morphological detail (see discussion of $H$. octoporus). As the type species of Harpagopalpellus, H. tetraporus is defined by the diagnostic characters of this subgenus. A further species probably belonging to the subgenus Harpagopalpellus (with the genital field placed between, not caudally from, $\mathrm{Cx}-4$ ) was described from India by Cook (1967). Because $H$. indicus is only known in the female sex and $H$. tetraporus only in the male sex, a discussion of their separation must be postponed until both sexes are known for each species. Apart from the geographical distance, the strong difference in size indicates that $H$. indicus is certainly not a synonym of $H$. tetraporus.

\begin{abstract}
Acknowledgements
The journey to Madagascar that produced the new records presented here was generously financed by Dave Cook (Paradise Valley, U.S.A.), who also made useful comments on a former draft of this paper. Tom Goldschmidt (Karlsruhe) was a reliable companion during field work and sorting of the collected material. Parts of the work was carried out during a stay at Muséum national d'Histoire naturelle, Paris. This visit found support in various ways from Mark Judson, curator of the mite collection, and was funded by the Synthesys programme of the European Community. Further support was given by Peter Jäger during a visit to Senckenberg Museum (Frankfurt) and by Jürgen Hevers (Braunschweig) who made available undissected specimens of $H$. tetraporus from the K.Viets vial collection. Mr Karl-Heinz Helmer (University of Tübingen, Department of Evolutionary Biology) prepared a specimen of $H$. $z e b u$ for SEM investigation, produced the photographs and gave helpful suggestions during an extended session. Mark Judson corrected language and contents of a former version of this paper. Christoph Allgaier (University of Tübingen, Department of Evolutionary Biology) assisted with the definitive layout and mounting of figures. The author extends his warm and sincere thanks to all these colleagues and institutions.
\end{abstract}

\section{References}

Cook D.R. 1966. - The water mites of Liberia. Mem. Amer. Ent. Inst. 6, III+1-418.

Cook D.R. 1967. - Water mites from India. Mem. Amer. Ent. Inst., 9 , III+1-411.

Cook D.R. 1974. - Water mite genera and subgenera. Mem. Amer. Ent. Inst., 21, VII + 1-860.

Lundblad O. 1941. - Eine Übersicht des Hydrachnellensystems und der bis jetzt bekannten Verbreitung der Gattungen dieser Gruppe. Zool. Bidr., 20, 359-379.

Viets K. 1924. - Diagnosen einiger neuer Hydracarinen. Zool. Anz. 58 (3-4), 103-106.

Viets K. 1925. - Nachträge zur Hydracarinen-Fauna von Kamerun. (Sammlungen aus Kamerun, Span. Guinea und Fernando Poo). Arch. Hydrobiol., 16, 197-242. 